\title{
Word-Final /כ̃/ In Greater Poland Polish: A CUMULATIVE CONTEXT EFFECT?
}

\author{
KAMIL KAŹMIERSKI \\ Adam Mickiewicz University \\ kkazmierski@wa.amu.edu.pl
}

MARTA SZLANDROWICZ

m.szlandrowicz@wp.pl

\begin{abstract}
An empirical corpus-based study of the likelihood of realizing the Polish nasal vowel / $/$ / word-finally as [om] (i.e. of 'nasal stopping') is presented. The goal was to verify whether the phenomenon exhibits a cumulative context effect, with words typically occurring in an environment favoring a particular phonetic variant showing higher rates of that variant regardless of environment. The results show that nasal stopping is more likely before stopinitial words than before words beginning in other sounds, if there is no intervening pause. Results with regard to the hypothesis that words typically followed by stops will show higher likelihood of nasal stopping, however, remain inconclusive.
\end{abstract}

Keywords: Polish, nasal vowels, cumulative context effect, corpus phonology

\section{Introduction}

Since at least SPE (Chomsky \& Halle, 1968), the standard view of lexical storage has been that non-contrastive phonetic detail has no place in phonological representations. Further iterations of generative phonology, including the nowdominant Optimality Theory (Prince \& Smolensky, 1993) also largely uphold this view. This 'abstractionist' approach to speech production assumes a feed-forward, modular architecture, as embodied in the speech production model proposed in Levelt et al. (1999).

A growing number of empirical findings have been challenging the assumptions that the phonological level operates on abstract units devoid of phonetic detail, and that speech production proceeds in discrete modules in a feedforward fashion. For example, effects of lemma frequency on phonetics such as Gahl (2008) are problematic for modularity. While a modular feed-forward architecture can deal with word-form frequency effects, it cannot deal with lemma frequency effects, since identical strings of phonemes, indistinguishable at the phonological level, should not be subject to disparate frequency effects. Further, 
evidence of morphological information influencing phonetics, such as Strycharczuk and Scobbie (2016) challenges the feed-forward architecture. Again, the phonological string is identical in each case, and the influence on phonetics of a module preceding phonology cannot be accounted for. Finally, a number of studies have reported "cumulative context" (Raymond, Brown, \& Healy, 2016) or "contextual frequency" (Forrest, 2017) effects, showing that the typical environment in which the tokens of a word occur influences its phonetic shape in other contexts as well. For instance, Seyfarth (2014) found that words that are typically predictable from context, are generally more reduced phonetically, even when a given token happens not to be predictable from its current context. Baumann and Ritt (2017) show that the development of noun - verb stress alternations in English as in 'convert. con' vert.V are successfully modeled by assuming that repeated adaptations to phrase-level rhythm have influenced lexical stress patterns. Eddington and Channer (2010) suggest that /t/-final words typically occurring in glotalling-favoring environment, i.e. typically followed by consonant-initial words, undergo glottaling more often than other words, even in other environments. Bybee (2017) dubbed the frequency of occurrence of a word in an environment conducive to a particular realization "FFC" ("Frequency in Favoring Conditioning"), spelling out the new view of influence of frequency on phonetic variation. It is the frequency of occurrence in a particular context, rather than overall frequency, that drives phonetic variation and change. Forrest (2017) makes a case that FFC should interact with overall frequency. Frequent words, he maintains, should be influenced by FFC, as their overall high frequency makes it possible for the effect of the typical environment to become sufficiently entrenched. Words that are less frequent, conversely, should be less prone to FFC, as the effect of their typical environment is not given enough chance to exert its force. The variation in the realization of word-final / $\tilde{\partial} /$ in Polish provides a testing ground for Forrest's hypothesis about the interaction of FFC and overall frequency. As described in more detail below, word-final / $/$ / has two main realizations, influenced by phonetic environment. Testing whether FFC, in an interaction with overall frequency, influences the realization of this variable could add to our understanding of the cumulative context effect.

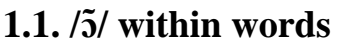

There are two types of nasal vowels (Dukiewicz, 1967): synchronic ("true" nasal vowels) and asynchronic. Synchronic nasal vowels are produced when the air is being released through both oral and nasal cavity throughout the entire duration of a segment; Northern French nasal vowels being a well-known example. The

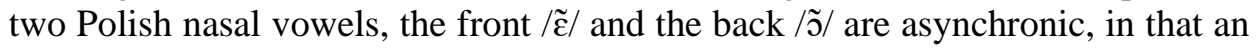
oral portion is followed by a nasalized portion, and their actual realization depends on their phonological environment, mainly on the following segment. / $\tilde{\text { / }}$ does not occur in word-initial position. Word-medially, before fricatives it is realized as a low back vowel followed by a nasalized labial-velar glide [ow]], e.g, dziąsło /' dəowiswo/ 'gum' (Dukiewicz, 1967; Dukiewicz \& Sawicka, 1995; Gussmann, 
2007). Wiśniewski (2000) points out that before alveolo-palatal fricatives, the

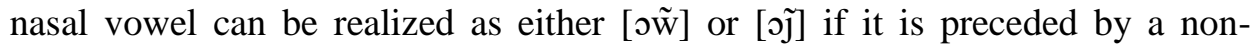
palatalized consonant, e.g. wąsik ['vow̃øik] ['voj̄cik] 'mustache', and as [õ̃] if it is preceded by a palatalized consonant, e.g. wiązie ['vjojze] 'elm-SG.LOC'. Before stops, the nasal vowel is typically realized as a sequence of an oral vowel [0] and a nasal stop homorganic with the following sound (Dukiewicz, 1967; Dukiewicz \& Sawicka, 1995; Gussmann, 2007; Wiśniewski, 2000). And so, before velars (and also post-palatals according to Wiśniewski (2000) and Gussmann (2007) the nasal vowel is realized as [oj], e.g., łąka ['wonka] 'meadow', before bilabials, the realization is [om] e.g. kappiel ['kompjel] 'bath', before (post)dentals it is [on] kąt [kont] 'angle', before retroflexes it is [on] łączyć ['wontșitc] 'connect', and before pre-palatals it is [on] wziąc [vzontc] 'take'. Before $/ \mathrm{l} /$ and /w/, / $/$ / is realized as a plain oral vowel /o/ wzią /vzow/ 'take3SG.PST'. Finally, the back nasal vowel also appears in word-final position. The realization typically given for this position (e.g. Dukiewicz, 1967; Dukiewicz \& Sawicka, 1995; Gussmann, 2007; Wiśniewski, 2000) is the same as that before fricatives, i.e. an oral vowel followed by a labial-velar nasalized glide, e.g. idą /'idow̃/ 'go-3PL.PR'. This view, however, glosses over the variation manifestly present in the realization of word-final / $/$.

\subsection{Variation in word-final / $/$ /}

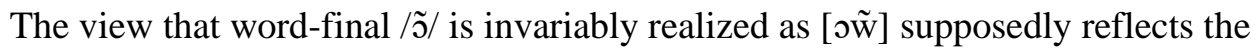
state of affairs in standard Polish. Alternate realizations of word-final / $\tilde{\mathrm{J}} /$, such as [om] , [ow] and [0] have long been noticed (Biedrzycki, 1978), but treated either as dialectal (and, implicitly or explicitly) unworthy of use in the public sphere (Dubisz, Karaś, \& Kolis, 1995; Dunaj, 2006; Madejowa, 1987) or even pathological (Madelska, 2005, p. 15). We are not going to engage in a discussion of what kind of ontological object the standard dialect of Polish is, and if there are any speakers who consistently speak it. Be that as it may, varieties of Greater Poland Polish have long been described as having [-om] for word-final / $\tilde{\mathrm{o}}$ / (Gruchmanowa, 2006). We will refer to this realization as 'nasal stopping'. Modern sociolinguistics has shown that the use of local pronunciation variants is hardly an all-or-nothing categorical affair, and that speakers can be expected to oscillate between the local and the supra-local, or 'standard' pronunciation. Consequently, we expect speakers from Greater Poland to show variation between

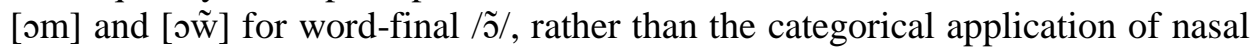
stopping.

Additionally, the absolute final position needs to be contrasted with wordfinal, but not utterance-final position. If an /亏̃/-final word is immediately followed by another word, with no pause in between, the two words may form a phonological word, and the generalizations described above for the word-internal environment might apply (Ostaszewska \& Tambor, 1990, p. 62). Hence, for example, we would expect [om] in są bojowe 'they are combative' but [ow̃] in są spokojne 'they are calm'. 


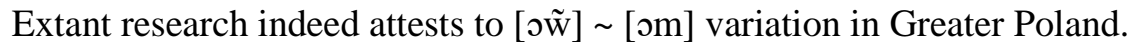
Witaszek-Samborska (1985) conducted an auditory investigation of recordings of everyday conversations of 43 educated speakers either native to or long-time ( > 30 years) residents of Poznań, the capital of Greater Poland. Three age-groups were compared: 20-34, 35-59 and 60-80. Nasal stopping was common, and 53\% of participants used nasal stopping exclusively or almost exclusively (particularly in the oldest generation). Seeking to complement Witaszek-Samborska's apparent-time study with real-time data, Kaźmierski, Kul and Zydorowicz (2019) measured the nasal stopping rate in 14 college students from Poznań, a group comparable to the youngest speaker group in Witaszek-Samborska's study. In Kaźmierski et al. (2019), only 3 out the 14 speakers had a nasal stopping rate above $50 \%$, and the overall nasal stopping rate was rather low (25\%). In a linguistics study, Baranowska and Kaźmierski (2020) investigated the association between the social variables of age, sex, education and location (urban vs. rural), as well as speaking style and the realization of Polish nasal vowels in the speech of 50 Greater Poland residents. Audio recordings were manually coded for the realization of word-final nasal vowels. The overall rate of nasal stopping was $18 \%$. The fitted probability of nasal stopping increased with older age, lower educational level, and decreased for the most highly educated group in a formal task (i.e. reading as opposed to speaking). These studies show that nasal stopping of word-final / $/$ / was present 30 years ago (Witaszek-Samborska 1985), continues its existence as a variable process to this day (Baranowska, 2018; Baranowska \& Kaźmierski, 2020), even though it might be slowly receding. Its frequency of occurrence is systematically influenced by a number of internal and external factors.

\subsection{Hypotheses}

Given that nasal stopping is a variable process influenced by phonetic context, it can be used to test Forrest's hypothesis. Using a speech corpus as a source can be expected to provide relevant data, as it (a) yields words occurring in varied phonetic environments and (b) contains relatively informal speech, conducive to local speech variants. We therefore decided to conduct a corpus study of variation in word-final / $\tilde{\jmath} /$, with the following hypotheses.

Hypothesis 1: When there is no pause between a word ending in / $\tilde{\mathrm{o}} /$ and the following word, the initial sound of the following word will influence the likelihood of nasal stopping: there will be more nasal stopping in favoring environments.

This hypothesis follows from (Ostaszewska \& Tambor, 1990, p. 62) claim that the initial consonant of the following word influences the likelihood of nasal stopping in the preceding word. A corroboration of this hypothesis will justify treating the tokens where the following word begins with a stop as instances of a favoring environment. 
Hypothesis 2: For high-frequency words ending in / $\tilde{\jmath} /$, their FFC (Frequency in Favoring Conditioning) will be positively correlated with their likelihood of nasal stopping.

Following Forrest (2017), we hypothesize that for high frequency words, FFC should be positively correlated with the likelihood to undergo nasal stopping.

\section{Data and method}

Data was extracted from the Greater Poland Spoken Corpus (Kul, Zydorowicz, \& Kaźmierski, 2020), henceforth GPSC. The corpus contains recordings of spontaneous speech of Polish native speakers from the area of Greater Poland. In this study, the speech of 64 participants was analysed: all speech present in the corpus that was furnished with orthographic transcripts at the time of the study was used. The majority of the speakers $(\mathrm{N}=51)$ were female as the participants recorded during the creation of the corpus were mostly students at the Faculty of English (Adam Mickiewicz University in Poznań), where male students are outnumbered by female students. All instances of word-final / $\tilde{\mathrm{s}} /$ were extracted from the corpus using the LaBB-CAT (Fromont \& Hay, 2012) suite. The data set, containing variables described in the following sections, was then fed into a mixed-effects logistic regression model using the lme4 package (Bates, Mächler, Bolker, \& Walker, 2015) in the R statistics environment (R Core Team, 2019).

\subsection{The response variable}

The token words were analysed in Praat (Boersma, 2018), both auditorily and visually. Each occurrence was coded as containing either a glide or a stop. Figure 1 and Figure 2 are spectrograms of illustrative examples. Figure 1 shows a realization with no stopping, i.e. with a nasalized glide. A general lowering of formants can be discerned, possibly due to increased lip rounding for the glide portion compared to the vowel portion. More importantly, the amplitude of the formants remains largely unaffected. 


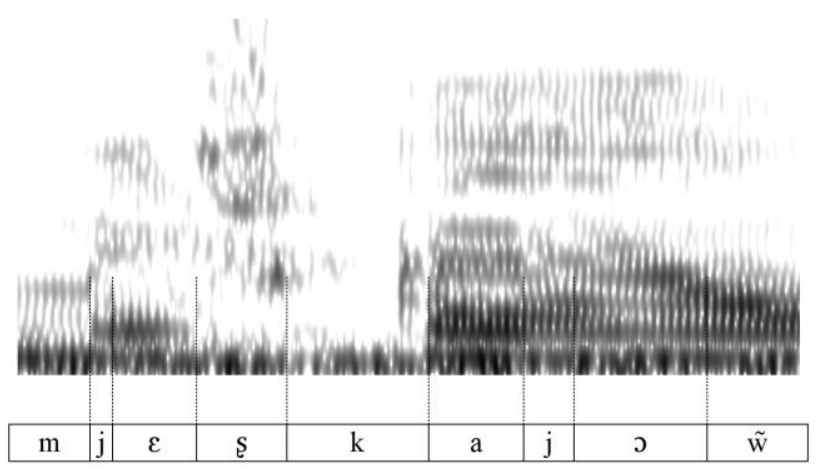

Figure 1. Spectrogram of mieszkają 'they live' realized without nasal stopping, i.e. with word-

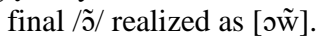

The example in Figure 1 contrasts sharply with the example shown in Figure 2. Figure 2 is a realization with nasal stopping, i.e. with a vowel followed by a nasal stop. With a nasal stop, the effect of nasality on the spectrum is much stronger than in the case of the glide realization. Visibly, the amplitude of all formants is lower compared to the vocalic portions, which is caused by the dampening effect of nasal antiformants on the resonances of the oral cavity.

Such spectographic evidence, coupled with an auditory inspection by the Second Author, a native speaker of the variety of Polish in question, was basis for the coding of the response variable: each instance was coded either as having undergone nasal stopping or not. Having a dichotomous response variable, we used logistic regression as the appropriate modeling tool.

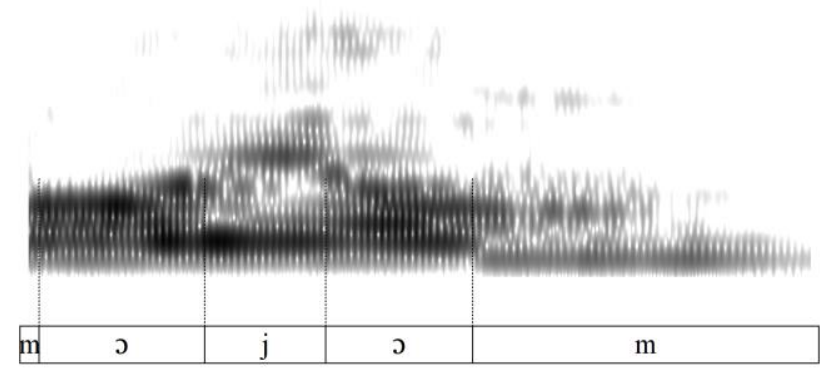

Figure 2. Spectrogram of moją 'my' realized with nasal stopping, i.e. with word-final /ow̃/ realized as [om]. 


\subsection{Variables pertaining to Hypotheses}

\section{FFC}

The key variable is Frequency in Favorable Conditioning (FFC). It was calculated

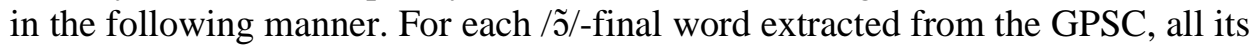
tokens where identified in the SUBTLEX-PL corpus (Mandera, Keuleers, Wodniecka, \& Brysbaert, 2015), to record all words following it. IPA transcriptions of these following words were needed to classify the environment as favorable to nasal stopping (the following word beginning with a stop) or not (the following word beginning with a fricative). First, a phonetic dictionary prepared during the creation of the GPSC was used. For the SUBTLEX-PL tokens absent from that dictionary, new IPA transcriptions were prepared with a perl script (Jarosz, Calamaro, \& Zentz, 2016; Jarosz \& Johnson, 2013). Finally, the sum of instances a given word is followed by stop-initial words in SUBTLEX-PL was divided by the sum of instances that word is followed by fricative-initial words, yielding the FFC variable. It was then centered and standardized.

\section{Favoring}

All tokens where the word is followed by a stop-initial word, e.g. są bloki /sõbloki/ 'be-3PL.PRS block.PL.NOM.' were coded as occurring in a favoring environment $(\mathrm{N}=450)$, all others $(\mathrm{N}=512)$ as not occurring in a favoring environment, yielding a binary Favoring variable.

\section{Frequency}

Log frequency information was retrieved from SUBTLEX-PL (Mandera et al., 2015), centered and standardized. Afterward, it was discretized into three categories: low, mid and high, using R's cut() function. This yielded a categorical Frequency variable with treatment coding and three levels. Mid was set as reference level.

\section{Pause}

Pause after / $/$ / was dichotomised as either present or absent, yielding a binary Pause variable.

\section{Pause:Favoring}

Since the influence of the initial sound of the following word is only expected when the two words are processed together, an interaction term involving the presence of pause and whether the environment was favoring was included. This Pause:Favoring interaction term is an operationalization of Hypothesis 1.

\section{FFC:Frequency}

Since the influence of FFC is only expected for high frequency words, an interaction term involving FFC and Frequency was included. This FFC:Frequency interaction term is an operationalization of Hypothesis 2. 


\section{Other variables}

\section{Gender}

Gender-driven stratification is well-known to influence phonetic variation, so a dichotomous Gender variable, based on self-reported gender of corpus speakers, was included.

\section{Location}

As the urban-rural dichotomy might influence phonetic variability, a dichotomous Location variable was included in the model.

\section{Mean rate}

As variable processes might be affected by speech rate, speech rate was included in the model, as two different terms. First, to model possible differences between habitually faster and habitually slower talking speakers, Mean rate, a continuous variable, was computed for each speaker. It was based on a syllables-per-second metric that each breath group in the corpus is annotated with, as calculated by LaBB-CAT.

\section{Rate deviation}

Further, to model the possibility that speeding up or slowing down relative to a speaker's habitual speaking rate is a relevant speaking rate variable (cf. Tanner, Sonderegger, \& Wagner, 2017), Rate deviation, a continuous variable, was used. It was calculated by taking the difference between the rate of the breath group in which a given token occurred and the mean speaking rate of the speaker, and dividing it by two standard deviations of speaking rate of that speaker.

\section{Random effects}

To account for the likely possibility that individual words have differing nasal stopping probabilities, a by-item random intercept for word was included. Similarly, to account for the likely possibility that individual speakers have differing nasal stopping probabilities, a by-subject random intercept for speaker was included (cf. Baayen, Davidson, \& Bates, 2008). Additionally, a by-speaker random slope for the variable of the most theoretical interest, FFC, was also included.

\section{Results}

\subsection{Empirical results: Individual variation}

Before considering the results of regression modeling, let us first consider empirical results with regard to individual variation. Figure ?? shows the rate of nasal stopping for each individual speaker. Speakers are displayed according to their nasal stopping rate, in descending order, with those having highest rates of nasal stopping at the top. The plot is split into rural speakers (left-hand panel) and urban speakers (right-hand panel). The urban-rural dimension seems to play no important role in influencing nasal stopping: in each panel, there are speakers spanning the entire hierarchy. The plots are also color-coded for gender. Gender does not seem to be an important variable, either, as speakers of both genders can 
be found throughout the hierarchy. Most strikingly, there is a tremendous amount of individual variation, spanning the range of $90 \%$ (Speaker 60) down to 5\% (Speaker 56), $\overline{\mathrm{x}}=53 \%$, sd $=19 \%$. This underlines the absolute necessity of accounting for individual variation with random terms.
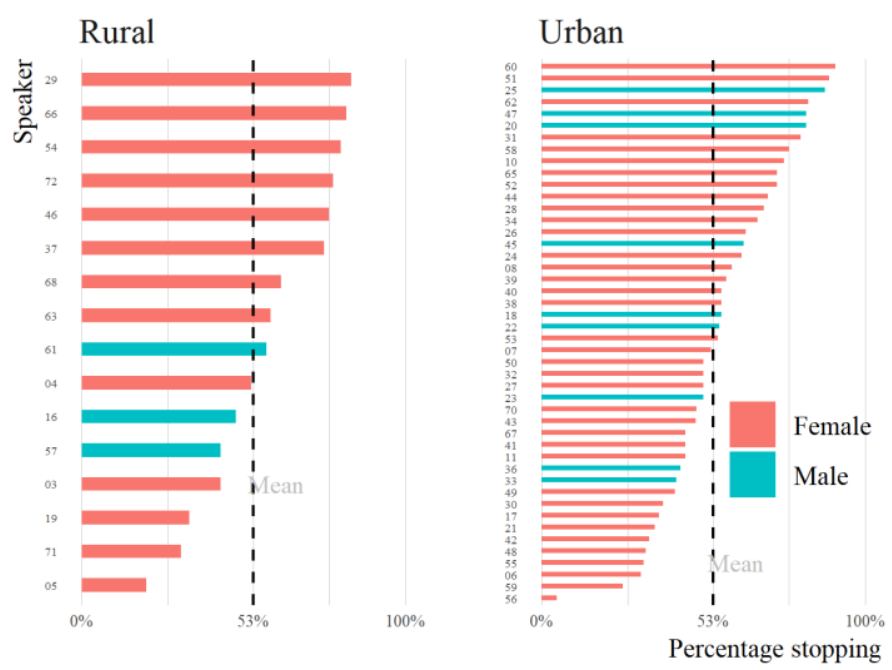

Figure 3. Rates of nasal stopping of individual speakers, color coded for gender.

\subsection{Regression modeling}

The mixed-effects logistic regression model fit to the data $(\mathrm{N}=962)$ converged with Marginal R2 of 0.082 and Conditional R2 of 0.182. Due to initial convergence issues, the bobyqa optimizer was used. The by-speaker random intercept had a standard deviation of 0.63 , and the by-item random intercept had a standard deviation of 0.00002 , attesting to vastly larger between-speaker than between-word variation. The predictors that reached statistical significance in the model are Frequency [Low] $(\mathrm{z}=-2.21, \mathrm{p}=0.027)$, Pause [Present] $(\mathrm{z}=4.4, \mathrm{p}<$ $0.001)$, Favoring [Yes] $(\mathrm{z}=6.84, \mathrm{p}<0.001)$ and an interaction term: Pause [Present]:Favoring [Yes] $(\mathrm{z}=-3.94, \mathrm{p}<0.001)$. A summary of all fixed effects in the model is presented in Table 1.

Table 1: Summary of fixed effects in the model.

\begin{tabular}{lcccc} 
Predictor & Log odds & SE & z-value & $\operatorname{Pr}(>|\mathbf{z}|)$ \\
\hline (Intercept) & 0.06 & 0.92 & 0.07 & 0.948 \\
FFC & 0.05 & 0.31 & 0.16 & 0.876 \\
Frequency [Low] & -0.45 & 0.21 & -2.21 & $\mathbf{0 . 0 2 7}$
\end{tabular}




$\begin{array}{lcccc}\text { Frequency [Mid] } & -0.13 & 0.17 & -0.78 & 0.434 \\ \text { Gender [Male] } & 0.02 & 0.28 & 0.08 & 0.935 \\ \text { Location [Urban] } & -0.10 & 0.26 & -0.39 & 0.697 \\ \text { Mean rate } & -0.11 & 0.26 & -0.43 & 0.669 \\ \text { Rate deviation } & -0.08 & 0.24 & -0.34 & 0.736 \\ \text { Pause [Present] } & 1.00 & 0.23 & 4.40 & <\mathbf{0 . 0 0 1} \\ \text { Favoring [Yes] } & 1.13 & 0.16 & 6.84 & <\mathbf{0 . 0 0 1} \\ \text { FFC : Frequency [Low] } & 0.06 & 0.33 & 0.18 & 0.858 \\ \text { FFC }: \text { Frequency [Mid] } & -0.26 & 0.33 & -0.79 & 0.431 \\ \text { Pause [Yes] : Favoring [Yes] } & -1.44 & 0.37 & -3.94 & <\mathbf{0 . 0 0 1}\end{array}$

All of the terms that are significant are either interaction terms or terms involved in interaction terms. Partial effect plots illustrating the predictors which have reached statistical significance in the model, i.e. the terms shown to be associated with the likelihood of $/ \tilde{\jmath} /$ to undergo nasal stopping $(/ \tilde{\jmath} / \rightarrow[\mathrm{\jmath m}])$, are presented in Figure 4. 
A

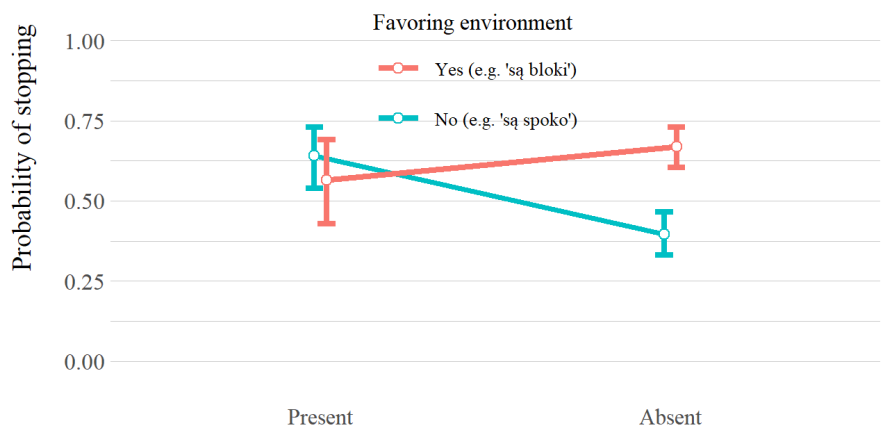

Pause

B

Frequency group

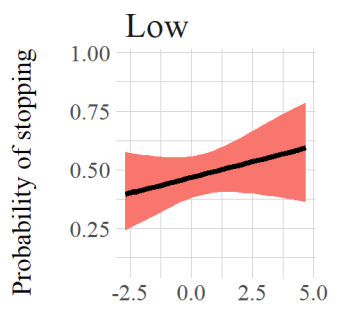

Mid

High
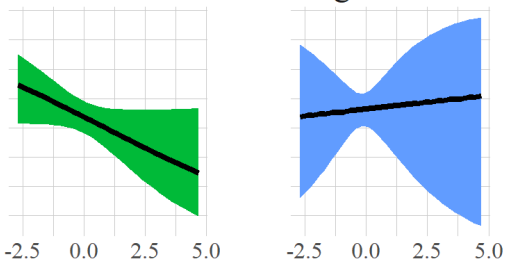

Frequency in Favoring Conditioning

Figure 4. Partial effect plots of the two interaction terms in the model. The error bars (Panel A) and error bands (Panel B) are 95\% confidence intervals.

Partial effect plots illustrating the predictors which are not statistically significant in the model, i.e. the terms not shown to be associated with the likelihood of / $\tilde{\partial} /$ to undergo nasal stopping $(/ \tilde{\mathrm{J}} / \rightarrow[\mathrm{\jmath m}])$, are presented in Figure 5. 
A

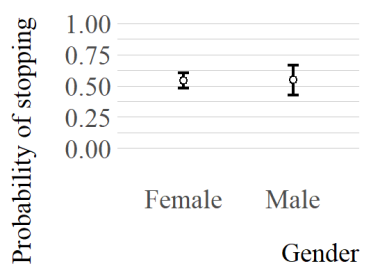

C

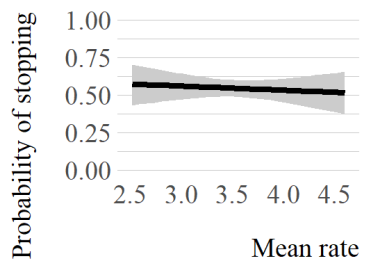

B

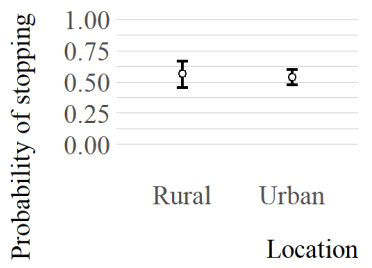

D

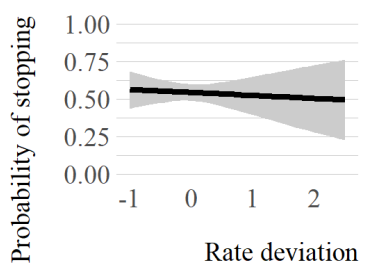

Figure 5. Partial effect plots of the terms not significant the model. The error bars (Panels A and B) and error bands (Panels C and D) are 95\% confidence intervals.

\section{Discussion}

The results corroborate Hypothesis 1 . The significance $(\mathrm{p}<0.001)$ of the term Favoring_Yes with a positive coefficient (1.13) shows that there is a higher likelihood of nasal stopping in the stopping-favoring environment. Since Favoring interacts with Pause, and since they are both treatment-coded, this effect holds for the reference level of Pause, i.e. when there is no pause. This is as expected: when the two words abut each other, the initial sound of the second word exerts its influence on the word-final / $\tilde{\partial} /$. That this influence is absent when there is an intervening pause is shown by the significance $(\mathrm{p}<0.001)$ of the Pause [Yes]:Favoring [Yes] term. Its negative coefficient (-1.44) completely undoes the simple effect of Favoring. This is clearly visible in Panel A of Figure 4. With the pause absent (right-hand side of the panel), the environment does make a difference, but with the pause present (left-hand-side of the panel), it does not.

With regard to Hypothesis 2, the results remain somewhat inconclusive, however. The sign of the coefficient for FFC for high frequency words (the reference level of Frequency) is positive (0.05), as predicted by the hypothesis. However, this model term is not significant $(\mathrm{p}=0.876)$. The model shows great uncertainty with estimating this coefficient, as is evident by looking at the confidence band for the predicted effect of FFC in high-frequency words in the bottom right-hand plot in Figure 4. The significant $(\mathrm{p}=0.027)$ negative coefficient $(-0.45)$ of Frequency [Low] shows that for at mean FFC values, low frequency 
words undergo less nasal stopping than high frequency words do. Perhaps with a larger, or more balanced data set a reliable estimation of the influence of FFC on high-frequency words would be possible. At present, however, no strong conclusions can be drawn in that regard.

In sum, we have tested the cumulative context effect on Greater Poland Polish data. In the process, we have positively established the influenced of favoring environment on the likelihood of nasal stopping, given there is no intervening pause. With regard to the main hypothesis (Hypothesis 2), which, if corroborated, would have contributed to the body of research challenging abstractionist, feed-forward models of speech production, our results remain inconclusive. Using an expanded data set, perhaps by furnishing the remaining part of the GPSC with transcriptions, would enable further research.

\section{References}

Baayen, R. H., Davidson, D. J., \& Bates, D. M. (2008). Mixed-effects modeling with crossed random effects for subjects and items. Journal of Memory and Language, 59(4), 390-412.

Baranowska, K. (2018). Nasal vowels in English and Polish. A comparative analysis and a sociolinguistic study (Master's thesis). Adam Mickiewicz University, Poznań.

Baranowska, K., \& Kaźmierski, K. (2020). Polish word-final nasal vowels: Variation and, potentially, change. Sociolinguistic Studies.

Bates, D., Mächler, M., Bolker, B., \& Walker, S. (2015). Fitting linear mixed-effects models using lme4. Journal of Statistical Software, 67(1), 1-48. https://doi.org/10.18637/jss.v067.i01

Baumann, A., \& Ritt, N. (2017). On the replicator dynamics of lexical stress: Accounting for stresspattern diversity in terms of evolutionary game theory. Phonology, 34(03), 439-471. https://doi.org/10.1017/s0952675717000240

Biedrzycki, L. (1978). Fonologia angielskich i polskich rezonantów. Porównanie samogłosek oraz spółglosek rezonantowych. Warsaw: Państwowe Wydawnictwo Naukowe.

Boersma, D., Paul \& Weenink. (2018). Praat: doing phonetics by computer [Computer program]. Version 6.0.41, retrieved 15 Aug 2018 from http://www.praat.org/.

Bybee, J. (2017). Grammatical and lexical factors in sound change: A usage-based approach. $\begin{array}{llll}\text { Language Variation } \quad \text { and 29(03), } & \text { 273-300. }\end{array}$ https://doi.org/10.1017/s0954394517000199

Chomsky, N., \& Halle, M. (1968). The sound pattern of English. New York: Harper \& Row.

Dubisz, S., Karaś, H., \& Kolis, N. (1995). Dialekty i gwary polskie. Warsaw: Wiedza Powszechna. Dukiewicz, L. (1967). Polskie gloski nosowe. Państwowe Wydawnictwo Naukowe.

Dukiewicz, L., \& Sawicka, I. (1995). Fonetyka i fonologia. Cracow: Instytut Języka Polskiego PAN.

Dunaj, B. (2006). Zasady poprawnej wymowy polskiej. Język Polski, 3, 161-172.

Eddington, D., \& Channer, C. (2010). American English has go? a lo? of glottal stops: Social diffusion and linguistic motivation. American Speech, 85(3), 338-351. https://doi.org/10.1215/00031283-2010-019

Forrest, J. (2017). The dynamic interaction between lexical and contextual frequency: A case study of (ING). Language Variation and Change, 29(02), 129-156. https://doi.org/10.1017/s0954394517000072

Fromont, R., \& Hay, J. (2012). LaBB-CAT: An Annotation store. In Proceedings of the australasian language technology association workshop (pp. 113-117). Dunedin, New Zealand.

Gahl, S. (2008). Time and thyme are not homophones: The effect of lemma frequency on word durations in spontaneous speech. Language, 84(3), 474-496. https://doi.org/10.1353/lan.0.0035

Gruchmanowa, M. (2006). Językoznawcze wędrówki nie tylko po Poznaniu. Poznańskie Towarzystwo Przyjaciół Nauk. 
Gussmann, E. (2007). The phonology of Polish. Oxford: Oxford University Press.

Jarosz, G., Calamaro, S., \& Zentz, J. (2016). Input frequency and the acquisition of syllable structure in polish. Language Acquisition, 361-399. https://doi.org/10.1080/10489223.2016.1179743

Jarosz, G., \& Johnson, J. A. (2013). The richness of distributional cues to word boundaries in speech to young children. Language Learning and Development, 9(2), 175-210. https://doi.org/10.1080/15475441.2011.641904

Kaźmierski, K., Kul, M., \& Zydorowicz, P. (2019). Educated Poznań speech 30 years later. Studia Linguistica Universitatis Iagellonicae Cracoviensis, 136(4), 245-264. https://doi.org/10.4467/20834624SL.19.021.11314

Kul, M., Zydorowicz, P., \& Kaźmierski, K. (2020). The Greater Poland Spoken Corpus: Data collection, structure and application. In M. Wrembel, A. Kiełkiewicz-Janowiak, \& P. Gąsiorowski (Eds.), Approaches to the study of sound structure and speech. Interdisciplinary work in honour of katarzyna dziubalska-kołaczyk (pp. 198-212). New York: Routledge.

Levelt, W. J. M., Roelofs, A., \& Meyer, A. S. (1999). A theory of lexical access in speech $\begin{array}{lllll}\text { production. Behavioral and Brain } & \text { Sciences, }\end{array}$ https://doi.org/10.1017/s0140525x99001776

Madejowa, M. (1987). Współczesna polska norma językowa w zakresie wymowy samogłosek nosowych. Studia Phonetica Posnaniensia, 1, 31-56.

Madelska, L. (2005). Słownik wariantywności fonetycznej współczesnej polszczyzny. Cracow: Collegium Columbinum.

Mandera, P., Keuleers, E., Wodniecka, Z., \& Brysbaert, M. (2015). SUBTLEX-PL: Subtitle-based word frequency estimates for Polish. Behavior Research Methods, 47(2), 471-483.

Ostaszewska, D., \& Tambor, J. (1990). Fonetyka i fonologia wspótczesnego języka polskiego. Warsaw: PWN.

Prince, A., \& Smolensky, P. (1993). Optimality Theory: Constraint interaction in generative grammar. ROA-537.

Raymond, W. D., Brown, E. L., \& Healy, A. F. (2016). Cumulative context effects and variant lexical representations: Word use and English final t/d deletion. Language Variation and Change, 28(02), 175-202. https://doi.org/10.1017/s0954394516000041

R Core Team. (2019). R: A language and environment for statistical computing. Vienna, Austria: R Foundation for Statistical Computing. Retrieved from https://www.R-project.org/

Seyfarth, S. (2014). Word informativity influences acoustic duration: Effects of contextual predictability on lexical representation. Cognition, 133(1), 140-155. https://doi.org/10.1016/j.cognition.2014.06.013

Strycharczuk, P., \& Scobbie, J. M. (2016). Gradual or abrupt? The phonetic path to morphologisation. Journal of Phonetics, 59, 76-91. https://doi.org/10.1016/j.wocn.2016.09.003

Tanner, J., Sonderegger, M., \& Wagner, M. (2017). Production planning and coronal stop deletion in spontaneous speech. Laboratory Phonology: Journal of the Association for Laboratory Phonology, 8(1), 1-39. https://doi.org/10.5334/labphon.96

Wiśniewski, M. (2000). Zarys fonetyki i fonologii wspótczesnego języka polskiego. Toruń: Wydawnictwo Uniwersytetu Mikołaja Kopernika.

Witaszek-Samborska, M. (1985). Regionalizmy fonetyczne w mowie inteligencji poznańskiej. Slavia Occidentalis, 17, 91-104. 